\title{
SOBRE CLASES Y FOTOGRAFÍAS DE NICANOR PARRA
}

\author{
Marcelo Porta \\ Fotógrafo y cineasta \\ mportai@hotmail.com
}

Todo comenzó con la decisión de estudiar Física e Ingeniería en la Universidad de Chile. Mis intereses eran duales, se batían a duelo el arte y la ciencia. Nunca fueron irreconciliables, pero en esa época yo era muy joven para entenderlo: hacia el fin de los años 80 , Chile tendía naturalmente a los extremos.

Grande fue mi sorpresa cuando en la Facultad de Ingeniería hacían clases de literatura Enrique Lihn y Nicanor Parra. Solo podía tomar un curso a la vez, si bien asistí a algunas "cátedras" de Lihn de forma irregular, fui un alumno regular del "Literatura I" de Nicanor Parra en 1988. Lihn fallece ese mismo año. Salimos en febrero de vacaciones después de "echar los estudiantes" al rector Federici y su plan de racionalización universitaria; pienso que esa misma fuerza del movimiento estudiantil del momento habría alcanzado probablemente para un "NO" masivo en plebiscito.

Nicanor Parra fue prácticamente toda una vida profesor de Matemáticas y Física, posteriormente dictó clases de Literatura para el Departamento de Estudios Humanísticos (DEH) de la Facultad de Ciencias Físicas y Matemáticas de la Universidad de Chile, entre 1972 y 1994. Sin abandonar su pasión por la ciencia, matemáticas y física, deviene antipoeta.

Creo que encontré en Parra un reflejo de mis cuestionamientos e inquietudes, alguien que había resuelto de gran manera ese puzzle de vida y vocación, un maestro a la usanza de los antiguos sabios que dominaban todas las áreas del conocimiento. Él, para nosotros, resolvía $\mathrm{E}=\mathrm{mc} 2$ desde la mecánica por un método que nadie había descubierto, como también escribía los más vanguardistas textos o artefactos visuales.

Yo tenía 18 años y Parra 74. Era lo más parecido a asistir a una "clase magistral", donde el profesor compartía ante los alumnos los intereses poéticos y científicos que desarrollaba en ese momento, usando el aula como un laboratorio, donde expandía su trabajo de investigación personal, que ese momento daba origen a los posteriores "Discursos de sobremesa". 
Poema-Problema o tarea para la casa:

¿Cuánto vale la Tierra a \$ el Gramo?

Y el que no me crea que la pese...

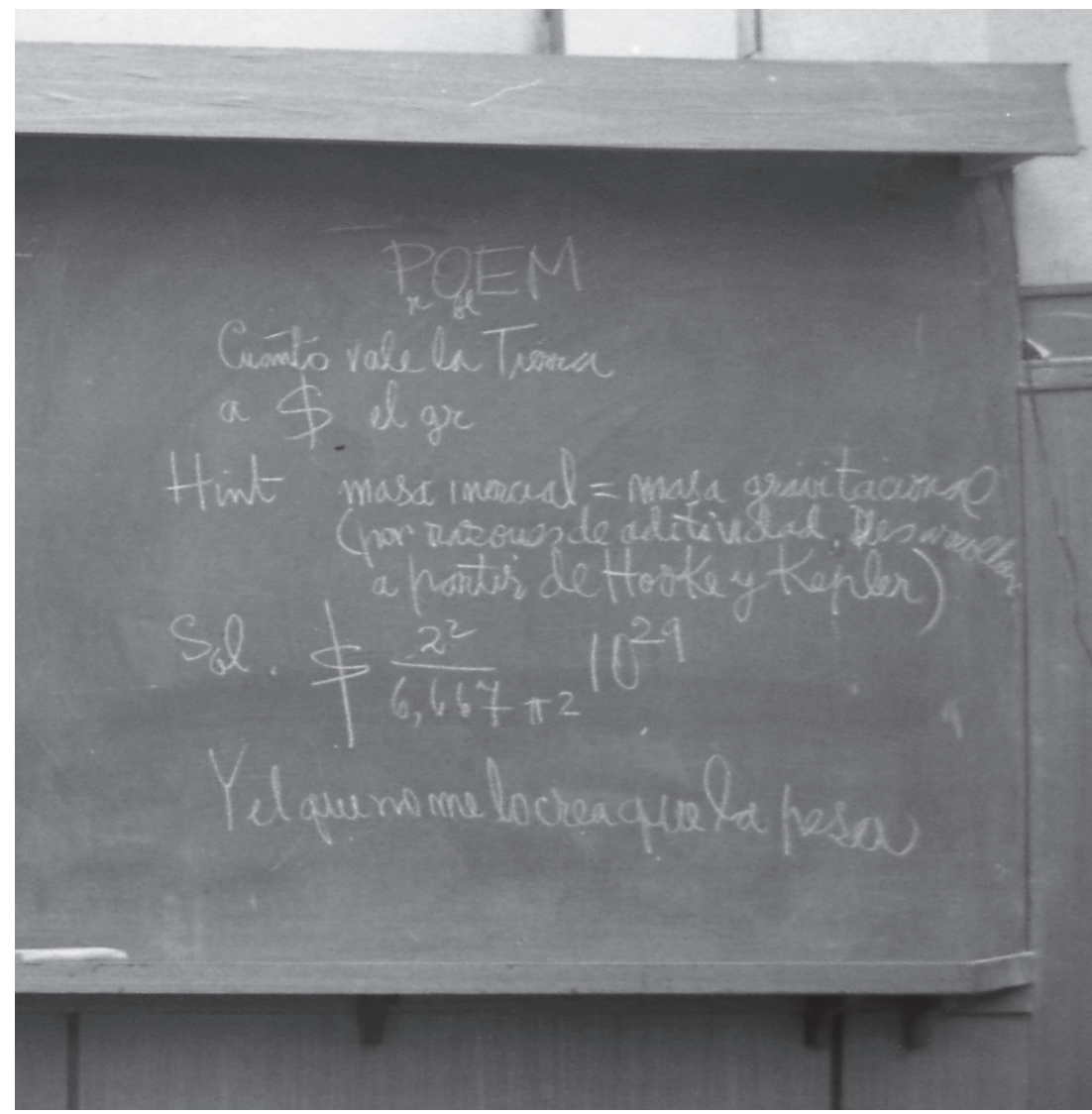

"Sea P una proposición verdadera se pide demostrar que es falsa" (recordemos que era año de plebiscito). Hace poco Nicanor me contó que lo había visitado el alumno que había resuelto esta contradicción en sus clases de los años 80 .

Recomendación a los alumnos, el libro "Chaos” (Caos), pregunta: ¿Cómo una mariposa en Pekín puede botar un rascacielos en Nueva York? Es una pregunta que hoy adquiere aún mayor relevancia. 
Durante los años posteriores seguí mi periplo dentro de la Universidad de Chile, que en los noventa fue -con todos sus problemas- un templo formativo. Eran años de vuelta a la democracia. Intenté por aquel tiempo ser físico o ingeniero.

Conozco en la Facultad a Darío Villalón, compañero de curso con quien montamos un taller de pintura, el cual funcionó en una sala del frontis de la Escuela de Ingeniería ubicada entre los símbolos arte y ciencia. Luego participó del taller de fotografía, tomó un curso de cine y colaboró en la Cinemateca de la Universidad. Darío me presentó a René Dintrans y ellos constituyeron el "Comando Autónomo", pegando papelógrafos de antipoemas y haciendo grafitis en la calle para promover a "Parra al Nobel" en 1992. Me reclutaron como fotógrafo y me presentaron formalmente a Nicanor. De dicho encuentro y posterior reunión, le propongo fotografiar las pizarras de la que sería su último semestre de clases a sus 79 años en 1993, el nombre del seminario: "Hamlet, Príncipe de Dinamarca". Me atrapó esa aula. Se hablaba de Shakespeare, Duchamp, Allen Ginsberg, Miro, Rimbaud, Enrique Lihn, Baudrillard, Morin, también de ecología. Prendido de su grafología, aquellos textos cuentan con una acabada propuesta estética, de puño y letra en tiza del antipoeta y antiprofesor.

Almuerzo con Parra los martes y los jueves después de las clases, vamos frecuentemente Darío, René, algunos alumnos y los hijos de Nicanor.

Comenzamos a cultivar en esos años una amistad que permitirá que siga fotografiando y filmando a Parra hasta el presente, sobre todo, una amistad y una obsesión que se convirtió en una gran excusa para disfrutar y aprender de su complicidad y sus profundas conversaciones.

El profesor deja escrito en la pizarra a sus alumnos su dirección y teléfono para que lo visitemos en su casa de Las Cruces. Fui un alumno privilegiado en aceptar esa invitación, visitándolo continuamente hasta el presente.

Parra nos dice en su última clase en 1993 (reproducción textual):

“...Hay que desconfiar de todo tipo de discurso, yo diría que esa es la conclusión de este seminario, hay que desconfiar de todo tipo de discurso, se acuerdan ustedes lo que Jean Baudrillard nos dice, ayer dedicamos prácticamente toda la sesión a ver qué pasa con el discurso conceptual que llama Baudrillard, dice que produce el colapso del discurso del discurso conceptual y antes se había producido el colapso del discurso literario o sea a la muerte de dios, se agrega la muerte de Nietzsche que anuncio la muerte de dios, y después se agrega la muerte prácticamente del autor, la muerte del texto. Repitamos que según Baudrillard en Europa en este momento no existe un tipo de discurso confiable. En Latinoamérica hay discursos, los intelectuales siguen haciendo ensayos pero según él, estos ensayos no corren porque consisten simplemente en una chatarra europea, se sigue repitiendo los que se decía años atrás en Europa y en Europa se ha dejado de hacer eso, o sea, estamos atrasados de noticias. Bastante espantosa la situación en que se encuentra el discurso, como lo podríamos llamar a este discurso, el discurso hecho con palabras, sin embargo yo pido disertaciones aquí con ustedes, para disertar hay que discursear, una disertación es un discurso, que es de una contradicción aparente, estuve pensado ayer en que es necesario decir algo al respecto, creo que lo que se puede decir es esto: Hay derecho a un discurso que opera en la segunda naturaleza, la primera naturaleza ya sabemos 
cual es, la segunda naturaleza la hemos llamado la civilización, existen ... abstractos que el hombre agrega a su naturaleza, vimos ejemplos de estos abstractos que son de todo orden, nosotros queremos pensar especialmente en los abstractos verbales, por ejemplo las obras de Homero son artefactos verbales, las obras de Shakespeare, están ahí y ya fueron descubiertos, y si agregamos a estos artefactos verbales los otros artefactos de la civilización tenemos lo que se llamamos la segunda naturaleza. Dentro de esta segunda naturaleza evidentemente nos podemos comportar de la misma manera como se comportan los animales frente a la primera naturaleza, a la naturaleza propiamente tal, ahí no hay problema, los animales no tienen problema de discurso frente a la naturaleza, y nosotros tampoco deberíamos tener problema frente a la segunda naturaleza, el discurso, la disertación que ustedes hacen aquí opera en el mundo de la civilización, en ese mundo que nosotros agregamos a la naturaleza, eso se puede seguir haciendo, informes etc., etc., de lo contrario tendríamos que quedarnos absolutamente callados, no se puede decir nada. Lo que no se puede decir, el discurso que está en crisis, el discurso que colapsó, es el discurso que permite agregar algo que no existía antes a esta segunda naturaleza, por ejemplo, perdonen que me refiera a mí mismo en este caso, yo personalmente he agregado algo a esa segunda naturaleza que son los antipoemas..."

En una visita a la casa de Parra el año 2014, en vísperas de su centenario, le conté que expondría fotografías suyas y filmaciones de sus clases. Le pregunto: “QQué enseñaría hoy a sus estudiantes?" "Mira, Marcelo, me responde, en esa época estábamos todavía atrapados por el discurso... Hoy, a los estudiantes yo les haría bailar cueca".

Sube el volumen de una "cueca apianada" que estábamos escuchando, se para y se pone a bailar delante de mí. 